\title{
Machines That Teach Better Than Books?
}

\author{
BY JAY W. STEIN
}

$\mathrm{O}^{\mathrm{T}}$ THER THAN THE PERSON of the teacher, most readers would probably consider the book itself as the best guide to learning. It is unlikely that they have given thought to machines that teach.

At a time of serious concern for the teacher shortage in schools and colleges, some civic leaders and educational administrators are ready to turn in any direction that offers a panacea. Federal and foundation moneys are readily available for experimentation with "automated teaching." There is a danger, however, of widespread adoption before adequate experimentation. Unless some of the claims are carefully examined and the book's role upheld, numberless students will soon be punching the buttons of a "spoon-fed" machine instead of turning the pages of books in selected variety. Machine teaching is prelude to a bookless generation.

At meetings of professional associations, educators are hearing and discussing assertions that machines not only can teach, but that they can do it better than "live" teachers, "who are over-burdened and subject to human foibles of inefficiency and bias." A panel speaker at the spring 1960 meeting of the Association for Higher Education of the National Education Association continued: "They are certainly better teachers than books, which do not teach at all."

The incredible totality of functions claimed for the machines is summarized in the following paragraph: "The teaching machine may present specific information to the student; examine the student on each piece of information as it is presented; correct the student's errors; provide additional explanation on points where the student has erred; verify the correctness of an answer when it is cor-

\author{
Dr. Stein is Administrative Associate to the \\ Vice President, Syracuse University.
}

rect; proceed automatically to the next point when the student has mastered the preceding point, keep detailed records of the progress of each student; and, perform all the stated functions as a controlled monitor with infinite patience and completely without bias."1

The machine that purports to perform this superhuman combination of teaching functions comes in several varieties. More than a half dozen firms from coast to coast have begun manufacture, under such trade names as the Programs Scanner of the Dyna-Slide Co. (Chicago) and the Visitutor of Hamilton Research Associates, Inc. (New Hartford, New York). Other firms include Foringer \& Company (Rockville, Maryland), Rheem Califone Corporation (Hollywood, California), and U. S. Industries, Inc. Western Design Division (Santa Barbara, California). Their advertising is slick and colorful; the language is unequivocal. They have strong backing from certain psychologists and school of education defenders of favorite versions of learning theories.

A typical machine is the approximate size of a portable typewriter and bears some similarity in appearance to a combination calculator and vendor. A campus newspaper likens it to a slot machine. The student presses a button or turns a crank or dial for the question to appear on a small screen or in a "scanning window." He writes his answer on a paper record or sheet. He retracts a lever, presses a button again, or turns the dial farther for the machine answer to appear, so that he may grade himself. If his

\footnotetext{
1 Automated Teaching Bulletin, I(1959), 25.
} 
answer is correct, he presses another button to proceed to the next question. If he is wrong he presses the key to score a wrong response. He then begins the next item. Books of no kind enter the scene or come into the picture during the "automated learning experience."

The teachers' presentation through the machine of questions and answers, problems to be solved, or exercises to be performed is called "programming." The full set of questions covering the material to be studied, together with any supplementary panels of pictures, graphs or diagrams is called the program. Students at their machines form a new classroom pattern, states a message from one firm, but the concept remains that of "the time-honored tutor-pupil relationship, combining the Cartesian idea of breaking down a problem to its smallest parts, and the Socratic method of teaching through enlightened questioning."

Widely acclaimed methods of programming information are associated with two teaching machines pioneers, Dr. B. F. Skinner of Harvard and Dr. Sidney Pressey of Ohio State University. The Skinner method requires the student to recall the correct answer suggested by the text material, construct the answer, and write it down before being presented the correct response. The Pressey principle requires a student to recognize the correct answer to a statement by choosing from several multiple-choice alternatives. The program material may merely inform the student whether he is right or wrong in his selection, or it may include with the choice selected an explanation for being right or wrong. A "vanishing" principle, especially useful for memorization, involves presentation of a complete item, such as a poem, and the subsequent removal of increasing portions of it until the student is able to reproduce the entire item without a prompt.

The secrets of success for the teaching machines dwell upon certain accumulating evidence from psychological research.
Learning is more effective when the student receives immediate knowledge of the results. Students learn what they want to learn and have difficulty in learning material which does not interest them. They must be motivated. "Automatic feedback" of the correct responses immediately informs the student of his progress, gives him a basis for revising his errors, and provides a "built-in motivation" to learn more.

Promotion of the teaching machine ranges between extremes of criticizing and endorsing other modern "mechanization" as suits the needs for professional and commercial adoption. The recipient of the advertising risks falling into confusion and then, from its sheer weight, succumbing to the adoption of machines on his campus. It is important that he listen carefully to the claims. In objection to the often raised criticism that machines are lacking in human understanding, the representative of one firm asserted that school buses, washroom facilities, and thermostatic heating systems are mechanical but no one objects to them on antihuman grounds. Similarly, the mechanical structure of aids for strengthening the eye movements for faster reading, of movie projectors, radios, television, and phonographs, of the printing press are noted as hardly contributing to an inhuman society. The teaching machine, states one sales pitch, is really "another mechanical or automated aid, along with many others, although the best."

On the other hand, according to A. A. Lumsdaine of the American Institute for Research, Pittsburgh, writing in AudioVisual Communication Review, ${ }^{2}$ teaching machines differ from films, television, and other audio-visual media in three ways: (1) the student responds continuously and actively, with practice and testing of each step to be learned; (2) the machine informs the student promptly alter

A. A. Lumsdaine, "Teaching Machines and Seltinstructional Materials," Audio-Visual Communication Review, VII (1959), 163-181. 
each response whether it is correct, allowing him to correct his errors; and (3) the student proceeds on an individual basis at his own rate.

Research aiming at further verification and confirmation of claims made for automated teaching is underway at a number of institutions, including Earlham and Hamilton colleges and Harvard, Indiana, Illinois, and Arizona State universities, and under various commercial and military auspices. According to a report of the Fund for the Advancement of Education Committee on the Utilization of College Teaching Resources, the experiments suggest that effective learning can take place without the presence of the teacher who has initially planned for and helped guide the student's learning experience. There is little doubt that the machines can be used for teaching.

The very important question which mechanizers have been hesitant to face remains: Can and do the machines teach and communicate better than books? Unlike the book, properly used, does the machine unduly fragmentize the student's learning, make him dependent on mechanized programming, and discourage independent thinking and questioning? Does it eliminate appreciation for the humanizing warmth of linking author and reader in a good book. Except for machine gadgetry and fanfare, one skeptic asked, is the student really receiving anything that he should not rather be receiving from a well-written book embodying, where pedagogically necessary, Cartesian and Socratic principles of learning? Research has not yet answered these questions. Book-minded people, however, can think of answers which offer satisfaction to anyone who learns and likes to read.

Teaching machines can never substitute for the teaching book because of their dependence on the book. The machines depend on printed (book) instructions for their invention, assemblage, maintenance, and improvement. They de- pend on teachers who read books in great numbers in order to get the necessary background for curriculum building, course presentation, test-making, and "program construction." They depend on the ability of the learner to read and understand the questions presented which, unless the result is to be sheer rote and verbalism, must relate to wide reading of books and other printed matter.

More important are the positions of the reviewer, historian, and librarian who can show that books have been effective "teachers" for generations and the insistence of the book reader and scholar that the book can do whatever is claimed for the machine and may do it better. The book can inform, stimulate, present questions and answers, explain the errors and verify the correct response, proceed gradually in step-by-step fashion, embody Cartesian and Socratic principles of learning, and do so "with infinite patience" and as "completely without bias" as any machine.

Books, it is said, fail to teach because they are "passive and unprogrammatic and dead." They do not communicate in a machine-lively way. Thus, students do not give them the respect necessary to assist learning. Such statements as these are highly unfair and presumptuous from the lips of a machine promoter. For, apart from flashes of light, clicks of sound and movement of rollers, tapes, and sheets, the machine is certainly quite "passive." These, no less than the "automatic" corrective measures in the programming, still depend upon an unpassive human being who pulls the levers and turns the dials for the activity.

Any discerning reader, writer, scholar, or teacher who has captured a motivation and purpose for reading also knows the spirit of its being active and alive. Books have, in fact, "moved mountains," transformed personalities, and "changed the world." Teaching machine promoters may not concede these achievements to books, but they do admit that books can 
be programmed and that "teaching machines" broadly defined include books written programmatically, "scrambled" books, punch boards, and various printed paper devices. John A. Barlow, coordinator, Self-instruction Project, Earlham College, stated that "Even a specially designed envelope in some cases fulfills the function."

Without motivation and purpose, any psychologist will admit, no machine use can result in effective learning any more than can book reading. Moreover, these come best from example. In listening to some "book-loving" objections to machine use, a psychology professor from an eastern university affirmed vigorcusly how much he, too, would like more students to read more books, how vital book reading was. But when asked whether he read books, he implied in a stammering negative that he read only books about teaching machines. While these so far hardly number a half dozen, the quantity in preparation is probably large. But he is hardly an example to motivate pupils to read in any "general" or "liberal" areas. Perhaps if he did read widely he, too, would know that books can teach.

Talk of machine substitution for books is all the more foolish when one asks the question, "What function does learning serve?" As much as any, it serves to help people read books, reports, newspapers, and magazines, and to read their contents with understanding. From proper under- standing, it assists clarity of expression in speaking and writing. The machine programmer may help certain students to improve in these communication skills, but it appears to be an indirect and diverting means to the end of literacy.

That the book is still not doing for knowledge and education as well and as much as it should is doubtless true. But this is no reason to say, "therefore the campus must mechanize and use its money for machines." It provides no basis for comments that in five or ten years our open shelves of library books on all topics, and the rooms for browsing and reserved reading will give way to "classrooms and laboratories" containing rows of booths or compartments, each tabling a machine before which the student sits in his very own private learning situation. It is no reason to say that a publisher's listings or bookseller's wares lack "teaching" values.

It is rather a reason for improving the book still further and teaching more students how to read intelligently. It is necessary to stress that while books may wear out after centuries, depending upon their use and care and the quality of their paper and binding, they never "break down," as the best of machines admittedly do. To paraphrase slightly the well known statement of Carlyle, "A true university library remains a collection of books and shows little possibility of becoming a collection of machines."

\section{New ACRL Committee}

Edmon Low, President of ACRL, announces the appointment of a special Advisory Committee to the President on Federal Legislation with the following membership: Lewis C. Branscomb, director of libraries. Ohio State University, Columbus; Robert B. Downs, dean of library administration, University of Illinois, Urbana; Frederick G. Kilgour, Iibrarian, Yale Medical Library, New Haven, Conn.; Richard H. Logsdon, director of libraries, Columbia University, New York; Stephen A. McCarthy, director of Iibraries, Cornell University, Ithaca, N. Y. President-elect Ralph E. Ellsworth will serve as an ex-officio member of the committee. 